\title{
Effects of Hydrogen Addition on Power and Emissions Outputs from Diesel Engines
}

\author{
Momen Sughayyer \\ Mechanical Engineering Department, Palestine Polytechnic University, Hebron, Palestine \\ Email: sughayyer@ppu.edu
}

Received 24 November 2015; accepted 19 January 2016; published 22 January 2016

Copyright (C) 2016 by author and Scientific Research Publishing Inc.

This work is licensed under the Creative Commons Attribution International License (CC BY). http://creativecommons.org/licenses/by/4.0/

(c) (7) Open Access

\begin{abstract}
Energy efficiency and environmental impact have become dominant topics in internal combustion engines development. Among many strategies to improve power and emissions outputs from diesel engines is the partial mix of hydrogen and air as fresh charge components to form extremely lean and homogenous mixture, which resist the spontaneous combustion, while diesel fuel is injected directly inside combustion chamber using the conventional fuel injection systems. This contribution presents an analytical and experimental investigation for the effects of adding hydrogen on diesel engines power output and the reduction of emissions. Parametric analysis is used based on lamped parameters modeling of intake manifold to estimate in cylinder trapped charge. The fuel energy flow to engine cylinders is compared for a range of loads and concentrations to simulate relevant case studies. Diesel fuel reduction for significant range of part-load operation can be achieved by introducing hydrogen, along with power improvement emission reductions are affected positively as well. This is achievable without compromising the engine maximum efficiency, given that most engines are operated at small and part-load during normal driving conditions, which allow for introducing more hydrogen instead of large quantities of excess air during such operation conditions that also can be further improved by charge boosting.
\end{abstract}

\section{Keywords}

Energy Efficiency, Power and Emissions, Diesel Engines, Hydrogen, Air-Fuel Ratio

\section{Introduction}

Currently, thermal systems are required to become energy efficient and produce less emission. Diesel engines are one of these systems that need to be considered for improvement in this respect. Hydrogen also is expected to become one of the most important fuels for reducing greenhouse gas emission problem in the near future. Based on the characteristics of both fuels, this contribution provides an insight into the possibility of improving 
diesel engines power and emissions outputs by hydrogen addition. The effectiveness of the proposed technique will be demonstrated analytically and experimentally.

Diesel engines are characterized by their carbon oxides, nitrogen oxides, soot, and particulate emissions. Related literature shows that introducing hydrogen to partially substitute diesel fuel charge will enhance engine performance [1]. It mainly helps to reduce carbon oxides emissions as a consequence to the optimized mixture characteristics due to hydrogen gaseous state. Other researchers have used Computational Fluid Dynamics to explore the changes in nitrogen oxides emissions in hydrogen-enriched diesel combustion over a range of operating conditions. Their results confirm that there is a notable reduction in exhaust emissions with increasing of hydrogen percentage [2]. Other authors show an example of measured in-cylinder pressure for hydrogen-diesel system. The obtained data indicates normal combustion of pilot fuel without pre-ignition and premixed combustion. But the pressure has the tendency to sudden increase since hydrogen with high auto-ignition temperature ignites after pilot ignition of diesel. This allows for using hydrogen without serious modification of already onboard installed diesel engines [3]. In different study [4], the lean combustion using hydrogen fuel has been considered. The result of that contribution indicates that hydrogen helps to optimize combustion process, which allows for extending the lean limit significantly due to the improvement of lean misfire limit. In addition, it shows that cycle-to-cycle variations are reduced due to better mixing and faster combustion. Another investigation presented in [5] concerns both pure hydrogen combustion under homogeneous charge compression ignition conditions and hydrogen-diesel combustion in a compression ignition engine. Various hydrogen doses are used to provide insight related to the impact on combustion knock intensity, mass fraction burned and heat release rate, in addition to engine durability. The presented results show that up to seventeen percentage of hydrogen can give positive effect on performance. The experimental investigations [6]-[9] have targeted the effect of using hydrogen on engine parameters such as injection timing, maximum brake thermal efficiency, and oxides of nitrogen. It concludes that port-injected hydrogen helps to increase in brake thermal efficiency of the engine with a greater reduction in emissions.

In the present contribution, the performance of diesel engine is considered using addition of hydrogen and based on mean value engine modeling oriented for power and emissions outputs improvement. Hydrogen gas is introduced into the intake manifold using the available gas fuelling techniques. The concept is based on continuous injection inside intake manifold where a central metering valve and distributor deliver vaporized hydrogen into the intake runners. For this purpose, engine coolant heat is used for hydrogen evaporation and to control its temperature. Allowing relatively low-temperature hydrogen gas into the intake manifold helps to cool the fresh charge, which increases the charge density and helps to reduce engine emissions. Lean mixture prevents backfiring into the intake ducts. Diesel fuel is injected directly inside the combustion chamber using the current fuelling technologies with some minor modifications to reduce diesel fuel flow, which will be replaced by hydrogen fuel flow [10]. Mixture combustion is realized by diesel combustion, given that, the hydrogen mixture is relatively very lean and exceeds misfire limit in Otto cycle based engines. Thus, it is possible to assume that combustion of hydrogen synchronized to that of the diesel. The trapped fuel energy is compared for a range of loads and concentrations. The analysis and experimental results bring about a clear insight into the proposed possibility of partially and economically improving diesel engines outputs by partial addition of hydrogen at part-loads.

\section{System Modeling}

For the purpose of this contribution, a lamped parameter based model for lean air-hydrogen mixture formation inside the intake manifold is developed. The presented modeling allows also for considering the possibility of exhaust gas recirculation. As for starting, it is enough accurate to consider that intake manifold as single capacity connected to the boosting system whenever there is one on the input side along with the EGR system. It is connected from the other side as output to the engine cylinders. This capacity exchanges heat to the surroundings to allow for isothermal conditions, which allows for the assumption that single pressure and single temperature values can be used to characterize the whole capacity state changes. Closed volume around the intake manifold to account for mass flow to the engine cylinders is used. Therefore, the rate of mass change inside this capacity can be given by the continuity equation as following:

$$
\frac{\mathrm{d} m_{m}}{\mathrm{~d} t}=\dot{m}_{i}-\dot{m}_{o}
$$


where $m_{m}$ is the intake manifold mass content, $\dot{m}_{i}$ is the input mass flow to the intake manifold, and $\dot{m}_{o}$ is the outflow to engine cylinders.

Assuming that all intake manifold air, hydrogen, re-circulated exhaust gas are perfect gases, the mass in this case can be expressed Equation (2).

$$
m_{m}=\frac{P_{m} V_{m}}{R_{m} T_{m}}
$$

where $P_{m}$ is the pressure, $T_{m}$ is the temperature, and $R_{m}$ is the gas constant of the manifold mixture, while $V_{m}$ is the manifold volume. Accordingly, the pressure rate of change inside the intake manifold is given by

$$
\frac{\mathrm{d} P_{m}}{\mathrm{~d} t}=\frac{R_{m} T_{m}}{V_{m}}\left(\dot{m}_{i}-\dot{m}_{o}\right)
$$

$R_{m}$ and $T_{m}$ of the mixture at the engine inlet valve can be found by Equation (4) and Equation (5), respectively, using the mixture corresponding variables of the air, hydrogen, and exhaust gas. The two equations are based on the implicit assumption that perfect and adiabatic mixing takes place in the intake manifold.

$$
\begin{gathered}
R_{m}=\frac{\dot{m}_{a} R_{a}+\dot{m}_{h} R_{h}+\dot{m}_{e} R_{e}}{\dot{m}_{a}+\dot{m}_{h}+\dot{m}_{e}} \\
T_{m}=\frac{\dot{m}_{a} c_{p, a} T_{a}+\dot{m}_{h} c_{p, h} T_{h}+\dot{m}_{e} c_{p, e} T_{e}}{\dot{m}_{a} c_{p, a}+\dot{m}_{h} c_{p, h}+\dot{m}_{e} c_{p, e}}
\end{gathered}
$$

where $\dot{m}_{a}$ is the air mass flow rate, $\dot{m}_{h}$ is the hydrogen mass flow, and $\dot{m}_{e}$ is the re-circulated exhaust gas mass flow. $T_{a}, T_{h}$, and $T_{e}$ are the air, hydrogen, and exhaust gas sources' temperatures, respectively. $c_{p, a}$, $c_{p, h}$, and $c_{p, e}$ are the air, hydrogen, and exhaust gas constant pressure specific heats, respectively. $R_{a}, R_{h}$, and $R_{e}$ are the air, hydrogen, and exhaust gas constants, respectively. The total mass flow into the intake manifold capacity depends mainly of the pressure differences between the source and the intake manifold, in addition, the flow restriction areas, which is given by

$$
\dot{m}_{i}=\dot{m}_{i, a}+\dot{m}_{i, h}+\dot{m}_{i, e}
$$

where $\dot{m}_{i, a}$ is the air mass flow rate, $\dot{m}_{i, h}$ is the hydrogen mass flow, and $\dot{m}_{i, e}$ is the re-circulated exhaust gas mass flow. For the purpose of this case modeling, it is sufficiently accurate to adopt subsonic flow through restriction modeling to account for the flow into the intake manifold. For subsonic flow, the airflow, hydrogen flow, and exhaust flow into the intake capacitance can be given by the following well known equations, respectively, which are given in [11] [12].

$$
\begin{gathered}
\dot{m}_{i, a}=\frac{C_{d, a} A_{v, a} P_{a}}{\sqrt{R_{a} T_{a}}}\left(\frac{P_{m}}{P_{a}}\right)^{\frac{1}{\gamma_{a}}}\left(\frac{2 \gamma_{a}}{\gamma_{a}-1}\left[1-\left(\frac{P_{m}}{P_{a}}\right)^{\frac{\gamma_{a}-1}{\gamma_{a}}}\right]\right)^{\frac{1}{2}} \\
\dot{m}_{i, h}=\frac{C_{d, h} A_{v, h} P_{h}}{\sqrt{R_{h} T_{h}}}\left(\frac{P_{m}}{P_{h}}\right)^{\frac{1}{\gamma_{h}}}\left(\frac{2 \gamma_{h}}{\gamma_{h}-1}\left[1-\left(\frac{P_{m}}{P_{h}}\right)^{\frac{\gamma_{h}-1}{\gamma_{h}}}\right]\right)^{\frac{1}{2}} \\
\dot{m}_{i, e}=\frac{C_{d, e} A_{v, e} P_{a}}{\sqrt{R_{e} T_{e}}}\left(\frac{P_{m}}{P_{e}}\right)^{\frac{1}{\gamma_{e}}}\left(\frac{2 \gamma_{e}}{\gamma_{e}-1}\left[1-\left(\frac{P_{m}}{P_{e}}\right)^{\frac{\gamma_{e}-1}{\gamma_{e}}}\right]\right)^{\frac{1}{2}}
\end{gathered}
$$

where $C_{d, a}, C_{d, h}$, and $C_{d, e}$ are coefficient of discharge for air, hydrogen and exhaust gas, respectively. $A_{v, a}$, $A_{v, h}$, and $A_{v, e}$ are restrictions flow areas for air, hydrogen and exhaust gas, respectively. $P_{a}, P_{h}$, and $P_{e}$ are the air, hydrogen, and exhaust sources' pressures, respectively. $\gamma_{a}, \gamma_{h}$, and $\gamma_{e}$ are the air, hydrogen, and exhaust specific heat ratios, respectively. For mass flow out of the intake manifold to engine cylinders, we can be 
based on mean value modeling, which is given by Equation (10) for the four stroke systems.

$$
\dot{m}_{o}=\eta_{v} \rho_{m} V_{d} \frac{N}{120}
$$

where $\rho_{m}$ is the intake manifold density, $\eta_{v}$ is the volumetric efficiency, $V_{d}$ is the displacement volume, and $N$ is the engine speed given in revolution per minute.

$$
\rho_{m}=\frac{P_{m}}{R_{m} T_{m}}
$$

For compression ignition engines and gasoline direct injection engines the volumetric efficiency, $\eta_{v}$, can be given by Equation (12) as indicated in [11]. Assuming perfect gases with constant specific heat ratio and isentropic processes, the volumetric efficiency can be considered pressure dependent.

$$
\eta_{v}=\frac{V_{c}+V_{d}}{V_{d}}-\frac{V_{c}}{V_{d}}\left(\frac{P_{e}}{P_{m}}\right)^{\frac{1}{\gamma}}
$$

where $V_{c}$ is the combustion chamber volume. Now, by substituting Equation (4), Equation (5), and Equation (11) in Equation (10) the following relation can be obtained:

$$
\dot{m}_{o}=\frac{\eta_{v} V_{d} N}{120}\left(\frac{P_{m}}{\left(\frac{\dot{m}_{a} R_{a}+\dot{m}_{h} R_{h}+\dot{m}_{e} R_{e}}{\dot{m}_{a}+\dot{m}_{h}+\dot{m}_{e}}\right)\left(\frac{\dot{m}_{a} c_{p, a} T_{a}+\dot{m}_{h} c_{p, h} T_{h}+\dot{m}_{e} c_{p, e} T_{e}}{\dot{m}_{a} c_{p, a}+\dot{m}_{h} c_{p, h}+\dot{m}_{e} c_{p, e}}\right)}\right)
$$

Rearranging Equation (13), the following quadratic relationship can be obtained:

$$
\begin{aligned}
& \dot{m}_{a}^{2}\left[c_{p, a} R_{a} T_{a}\right]+\dot{m}_{a}\left[\dot{m}_{h}\left(c_{p, h} R_{a} T_{h}+c_{p, a} R_{h} T_{a}\right)+\dot{m}_{e}\left(c_{p, e} R_{a} T_{e}+c_{p, a} R_{e} T_{a}\right)-\frac{\eta_{v} V_{d} P_{m} N}{120} c_{p, a}\right] \\
& +\left[\dot{m}_{h}^{2} c_{p, h} R_{h} T_{h}+\dot{m}_{h} \dot{m}_{e}\left(c_{p, e} R_{h} T_{e}+c_{p, h} R_{e} T_{h}\right)+\dot{m}_{e}^{2} c_{p, e} R_{e} T_{e}-\dot{m}_{h} c_{p, h} \frac{\eta_{v} V_{d} P_{m} N}{120}\right]=0
\end{aligned}
$$

For the purpose of this study, it is assumed that there is no exhaust re-circulation, $\dot{m}_{e}=0$. Thus, it is possible to relate hydrogen flow to airflow inside the intake manifold by the following relation:

$$
\dot{m}_{a}=A F R_{h} \dot{m}_{h}=\lambda_{h} A F R_{s, h} \dot{m}_{h}
$$

where $A F R_{h}$ is the air/hydrogen fuel mass flow ratio, $A F R_{s, h}$ is the air/fuel stoichiometric ratio, and $\lambda_{h}$ is the excess air factor inside the intake manifold.

For physical parameters, the expression of the air mass flow can be given by Equation (16), if the fuel's temperature, specific heat, and gas constant are known.

$$
\dot{m}_{a}=\frac{\frac{\eta_{v} V_{d} P_{m} N}{120}\left(c_{p, a}+\frac{c_{p, h}}{A F R_{h}}\right)}{c_{p, a} R_{a} T_{a}+\frac{c_{p, h} R_{a} T_{h}+c_{p, a} R_{h} T_{a}}{A F R_{h}}+\frac{c_{p, h} R_{h} T_{h}}{A F R_{h}^{2}}}
$$

To account for air mass trapped inside engine cylinder, which is the available portion for the combustion of the injected diesel fuel. Therefore, it is possible to assume that all introduced hydrogen will be burned according to stoichiometric conditions. Based on that, all the rest air trapped could be used for diesel combustion as follows:

$$
\dot{m}_{a}=A F R_{d} \dot{m}_{d}+A F R_{s, h} \dot{m}_{h}
$$

To account for diesel fuel flow, which is injected inside cylinders, the following relation can be obtained by rearranging Equation (17). 


$$
\dot{m}_{d}=\dot{m}_{a}\left(\frac{\lambda_{h}-1}{\lambda_{h} \lambda_{d} A F R_{s, d}}\right)
$$

where $\lambda_{d}$ is the excess air factor inside the engine cylinder excluding the portion required for stoichiometric hydrogen combustion. While to account for the total trapped fuel energy content, Equation (19) can be used

$$
\dot{Q}_{c}=\dot{m}_{d} L H V_{d}+\dot{m}_{h} L H V_{h}
$$

Equation (19) helps to give insight into the available energy for producing useful power from introducing hydrogen and reducing diesel, though increasing this amount will increase the efficiency. Of course, maintaining or increasing this amount by replacing diesel by hydrogen will satisfy the sought target.

\section{Simulation}

In this section, the developed modeling will be used to analysis the effects of partially adding hydrogen in the induction system on the charge concentrations and the total fuel energy flow to the diesel engine. At first, the effect on charge trapped quantity is considered at various hydrogen concentrations to give insight on the effect of its gaseous state on the fresh charge composition. Then the effect of varying relative air-fuel ratio for both fuels on diesel mass flow is considered to allow for relating the three working fluids at various engine loads. After that, fuel energy flow to engine cylinders at various loads in the form of excess air factor is considered, followed by considering the effect of manifold pressure variation to give insight into possibility of increasing hydrogen flow.

For the purpose of this study, engine speed is kept constant as its main effect is on volumetric efficiency and for not complicating results analysis. Table 1 gives the main parameters used for simulation.

Figure 1 show the variation of hydrogen mixing increases for constant speed and diesel air-fuel ratio of in the form of excess air factor, $\lambda_{d}=4, N=2000 \mathrm{rpm}, P_{m}=1 \mathrm{bar}, T_{a}=300 \mathrm{~K}, T_{h}=300 \mathrm{~K}$. The addition of hydrogen gas reduces the fresh air mass flow to engine cylinders, which reduces the possibility of burning diesel fuel, given the fact that diesel engines always operate with excess air due to their smoke limit it will not affect fresh air needs at part-loads. In fact, experimental results available in literature proved that the presence of hydrogen mixing process with air, the mixture properties improve and helps to reduce the duration of combustion process. The volumetric efficiency decreases with load as the percentage of hydrogen increases for constant speed due to the effect of hydrogen gaseous state, which reduces airflow through the inlet manifold.

Therefore, specific diesel fuel consumption decreases with load as the percentage of hydrogen partial mixing increases at constant engine speed. Due to the mixing of hydrogen with air, more efficient burning process of fuel mixture is achievable, which could increases engine power, given the brake mean effective pressure increases with load when the percentage of hydrogen mixing increases.

Figure 2 shows the variation of hydrogen relative air-fuel ratio with diesel mass flow at various excess air factors. According to the presented literature review, introducing hydrogen could help in enhancing fuel and air

Table 1. Diesel engine and working fluids parameters [10] [12].

\begin{tabular}{ccc}
\hline Parameter & Symbol & Value \\
\hline \multirow{2}{*}{ Engine } & $V_{d}\left(\mathrm{~cm}^{3}\right)$ & 2151 \\
& $N(\mathrm{rpm})$ & 2000 \\
& $r_{c}$ & $19: 1$ \\
\hline Diesel Fuel & $A F R_{s}(\mathrm{~kg} / \mathrm{kg})$ & 14.5 \\
& $\mathrm{C}_{10.8} \mathrm{H}_{18.7}$ & \\
& $L H V(\mathrm{MJ} / \mathrm{kg})$ & 42.5 \\
\hline Hydrogen Fuel & $A F R_{s}(\mathrm{~kg} / \mathrm{kg})$ & 34.3 \\
& $C_{p}(\mathrm{~kJ} / \mathrm{kg} \cdot \mathrm{K})$ & 14.21 \\
& $L H V(\mathrm{MJ} / \mathrm{kg})$ & 120 \\
\hline
\end{tabular}



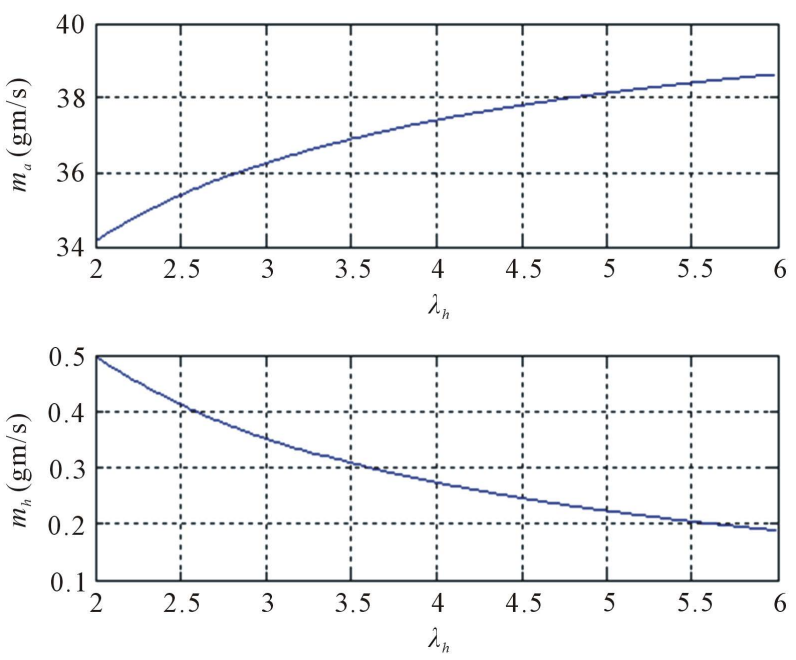

Figure 1. Variation of air and hydrogen mass flow with hydrogen relative air fuel ratio.

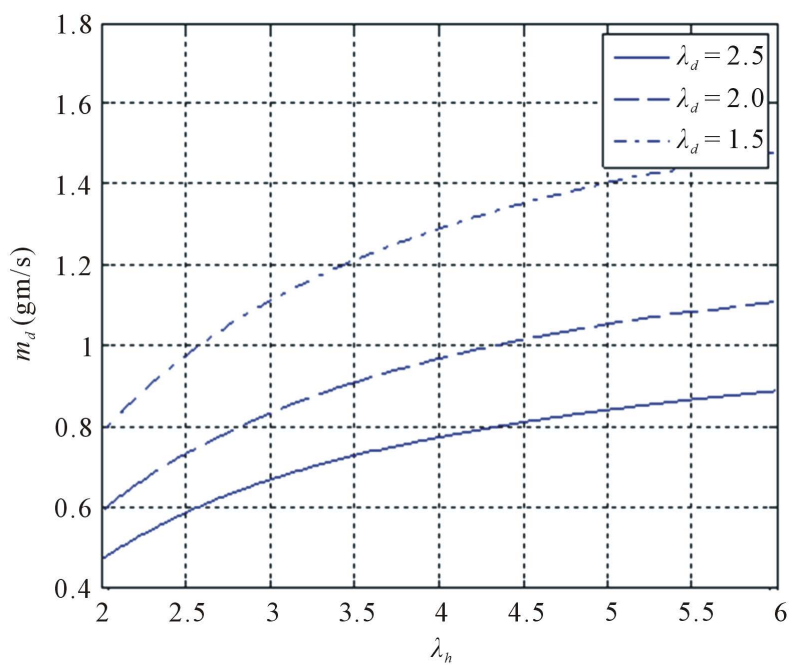

Figure 2. Variation of diesel mass flow with hydrogen and diesel relative air fuel ratio.

mixing, which gives better combustion characteristics; therefore, it becomes possible to use lower excess air factor for diesel. This allows for higher hydrogen induction rate for various loading of diesel engine running at constant speed. For duel fuel system, the equivalence ratio decreased as hydrogen induction rate increased for a given load and speed.

Figure 3 shows the variation of trapped fuel energy with hydrogen and diesel flow to engine cylinders at various engines loads in relation to diesel excess air factors. The results are for $\lambda_{h}=4, N=2000 \mathrm{rpm}, P_{m}=1 \mathrm{bar}, T_{a}=$ $300 \mathrm{~K}, T_{h}=300 \mathrm{~K}$. The induction rate for various loading of diesel engine at constant speed shows that it is possible at part-load to maintain or reduce diesel flow at lower excess air factor given that it will be higher than that for smoke limit. This allows for more introduction of hydrogen reducing the diesel consumption for the same load as the energy balance can be shifted to hydrogen flow.

The general trend is consistent with that observed in Figure 4. For diesel-hydrogen duel fuel system, the energy flow variation with the intake manifold pressure. The presented results are for $\lambda_{h}=4, \lambda_{d}=4, N=2000 \mathrm{rpm}, T_{a}$ $=300 \mathrm{~K}, T_{h}=300 \mathrm{~K}$, for certain diesel mass flow increasing manifold pressure allow for higher hydrogen mass flow rate. This could be very useful technique to improve the whole operating range of the diesel engine in question. 

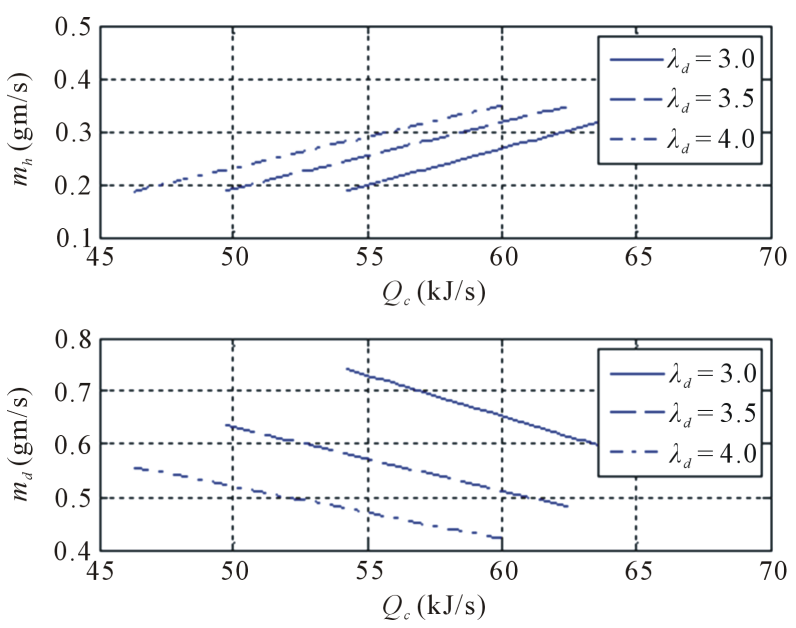

Figure 3. Variation of in-cylinder fuel energy with fuels mass flow and relative air-fuel ratio.
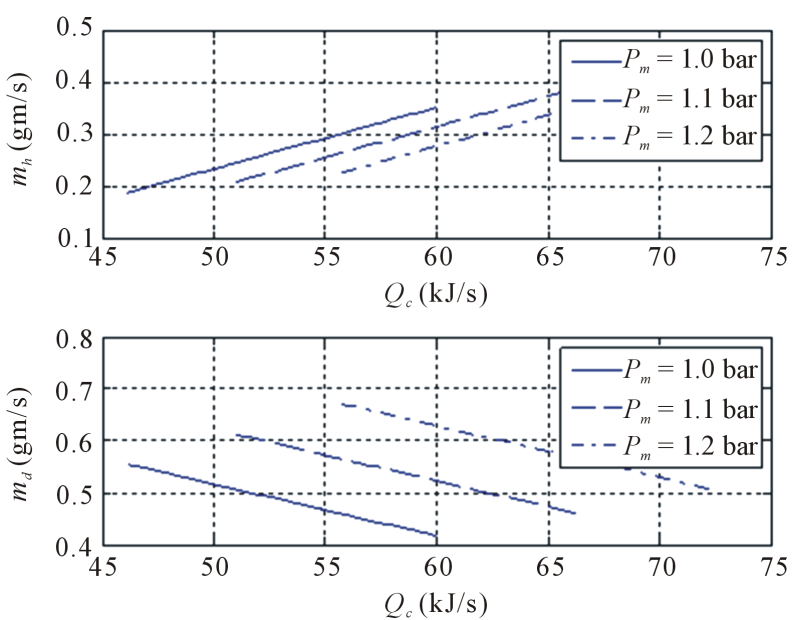

Figure 4. Variation of in-cylinder fuel energy with fuels mass flow with intake manifold pressure.

\section{Experimentation}

Figure 5 shows the testing setup that is used to validate the proposed method. It is composed of a multi cylinder diesel engine with an added on hydrogen gas supply system. It allows for manual regulating the hydrogen flow to the engine intake manifold. The setup also includes a hydraulic dynamometer for loading the engine in addition to engine speed measurement device.

The experimental procedure is designed to validate that using hydrogen gas a part-load could improve diesel engine power with less emissions. To achieve hydrogen this goal, hydrogen was introduced at constant engine speed and constant diesel flow. By increasing the load using the dynamometer, the difference of extra power generated from hydrogen addition is then measured. The experimental results for different tests, which are presented in Table 2, are obtained by the author and his students as part of this study [13].

\section{Results Discussion}

To increase cylinder energy content from fuel without increasing diesel fuel flow, it is possible to achieve that in two ways. The first one is to lower the excess air factor at part-load operating conditions allowing for more hydrogen mass flow. Figure 3 shows that $m_{d}=0.5 \mathrm{gm} / \mathrm{s}, Q_{c}=52 \mathrm{~kJ} / \mathrm{s}$ at $m_{h}=0.21 \mathrm{gm} / \mathrm{s}, \lambda_{h}=4, \lambda_{d}=4, N=2000$ $\mathrm{rpm}, T_{a}=300 \mathrm{~K}, T_{h}=300 \mathrm{~K}$. But, when $\lambda_{d}=3.5, Q_{c}=61 \mathrm{~kJ} / \mathrm{s}$ and $m_{h}=0.32 \mathrm{gm} / \mathrm{s}$, with other parameters 

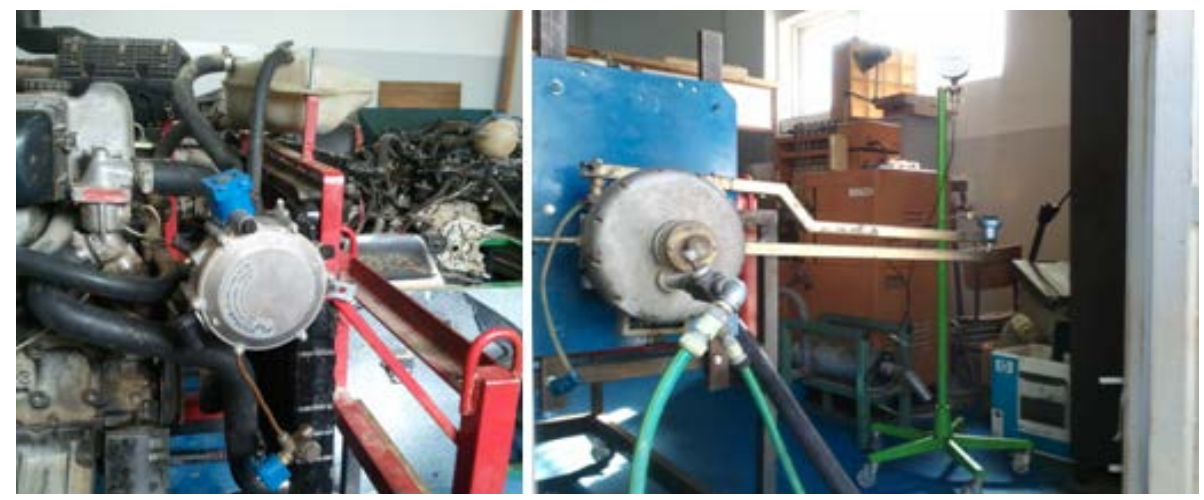

Figure 5. Test setup with the loading unit on right and hydrogen supply system on left.

Table 2. Experimental results for diesel engine with and without hydrogen.

\begin{tabular}{|c|c|c|c|c|c|}
\hline \multirow{2}{*}{$\begin{array}{l}\text { Speed } \\
\text { (rpm) }\end{array}$} & \multicolumn{2}{|c|}{ Diesel Only } & \multicolumn{3}{|c|}{ Diesel and Hydrogen Mixture } \\
\hline & $\begin{array}{l}\text { Torque } \\
(\mathrm{N} \cdot \mathrm{m})\end{array}$ & $\begin{array}{l}\text { Power } \\
(\mathrm{kW})\end{array}$ & $\begin{array}{l}\text { Hydrogen } \\
\left(\mathrm{cm}^{3} / \mathrm{s}\right)\end{array}$ & $\begin{array}{l}\text { Torque } \\
(\mathrm{N} \cdot \mathrm{m})\end{array}$ & $\begin{array}{c}\text { Power } \\
(\mathrm{kW})\end{array}$ \\
\hline \multirow{3}{*}{950} & \multirow{3}{*}{20} & \multirow{3}{*}{1.98} & 2.1 & 24 & 2.38 \\
\hline & & & 5.25 & 28 & 2.78 \\
\hline & & & 7.36 & 33 & 3.28 \\
\hline \multirow{3}{*}{1200} & \multirow{3}{*}{34} & \multirow{3}{*}{4.27} & 2.1 & 39 & 4.9 \\
\hline & & & 5.25 & 41 & 45 \\
\hline & & & 7.36 & 58 & 9.71 \\
\hline \multirow{3}{*}{1600} & \multirow{3}{*}{45} & \multirow{3}{*}{7.53} & 2.1 & 49 & 8.21 \\
\hline & & & 5.25 & 56 & 9.38 \\
\hline & & & 7.36 & 58 & 9.71 \\
\hline
\end{tabular}

are kept constant. This indicates that more power could be achieved at part-load condition by increasing hydrogen flow. Of course, this is very positive issue as most of engines installed onboard are operated within its part-load range. To have more insight into the effect of increasing hydrogen flow at part-load conditions, adiabatic combustion is considered. It is used to evaluate the adiabatic flame temperature $T_{c}$, given it is a direct indicator of the engine indicated power; a higher obtained temperature means a higher indicated power output. Based on this fact, constant pressure system is considered as given by

$$
\sum_{P} n_{i} \tilde{h}_{i}\left(T_{c}\right)=\sum_{R} n_{i} \tilde{h}_{i}\left(T_{1}\right)
$$

Equation (20) can be rearranged to obtain Equation (21), which is more suitable for using JANAF thermodynamic properties tables.

$$
\sum_{P} n_{i}\left(\tilde{h}_{i}\left(T_{c}\right)-\tilde{h}_{i}(298 \mathrm{~K})\right)=\sum_{R} n_{i}\left(\tilde{h}_{i}\left(T_{1}\right)-\tilde{h}_{i}(298 \mathrm{~K})\right)-\left[\sum_{P} n_{i} \tilde{h}_{f, i}^{o}-\sum_{R} n_{i} \tilde{h}_{f, i}^{o}\right]
$$

The chemical reaction is given by the flowing equation, which is based on complete combustion of the introduced fuel (Diesel and Hydrogen) in the presence of excess air.

$$
\begin{aligned}
& n_{d} \mathrm{C}_{10.8} \mathrm{H}_{18.7}+n_{h} \mathrm{H}_{2}+\left\{\left(10.8+\frac{18.7}{4}\right) n_{d} \lambda_{d}+n_{h}\right\}\left(\mathrm{O}_{2}+3.773 \mathrm{~N}_{2}\right) \\
& \rightarrow 10.8 n_{d} \mathrm{CO}_{2}+\left(\frac{18.7}{4} n_{d}+n_{h}\right) \mathrm{H}_{2} \mathrm{O}+3.773\left\{\left(10.8+\frac{18.7}{4}\right) n_{d} \lambda_{d}+n_{h}\right\} \mathrm{N}_{2}+\left(\lambda_{d}-1\right)\left(10.8+\frac{18.7}{4}\right) n_{d} \mathrm{O}_{2}
\end{aligned}
$$


From the equation above, it is very clear that excess air adds many moles of diatomic molecules $\left(\mathrm{O}_{2}\right.$ and $\left.\mathrm{N}_{2}\right)$ into the products that does not contribute to heat release just soaks it up. Therefore; the above discussed case is also considered for evaluating adiabatic flame temperature. Look up enthalpy values from JANAF tables, and iteration gives for $\lambda_{d}=4$, the obtained $T_{c}=1920 \mathrm{~K}$, but when excess air is reduced to $\lambda_{d}=3.5, T_{c}=1980 \mathrm{~K}$. It is obvious that allowing for more hydrogen flow at part-load helps to increase power output and reduce carbon emissions for certain engine load and speed. For evaluating $T_{1}$, isentropic compression is assumed for calculations simplicity.

The second way is to increase manifold pressure while keeping diesel flow constant, this allows to increase hydrogen flow as can be seen in Figure 4. If $m_{d}=0.5 \mathrm{gm} / \mathrm{s}$ at $P_{m}=1 \mathrm{bar}, Q_{c}=52 \mathrm{~kJ} / \mathrm{s}$ at part load with $\lambda_{h}=4$, $\lambda_{d}$ $=4, N=2000 \mathrm{rpm}, T_{a}=300 \mathrm{~K}, T_{h}=300 \mathrm{~K}$, for this case it needs $m_{h}=0.25 \mathrm{gm} / \mathrm{s}$, but if manifold pressure increased to become $P_{m}=1.1$ bar, more hydrogen could be introduced for the presence of more fresh air, so $Q_{c}=$ $62 \mathrm{~kJ} / \mathrm{s}$ using same diesel quantity while we are able to use $m_{h}=0.42 \mathrm{gm} / \mathrm{s}$ of hydrogen fuel, which increase significantly the use of clean energy in diesel powered vehicles.

Experimental results shows obvious increase in power output with introduction of hydrogen, which means that diesel consumption rate could be decreased with increase in hydrogen flow. This leads to decrease in carbon oxides emission by a very significant percentage. Further, to reduce the risk of hydrogen mixture auto-ignition, it is possible to benefit from the introduction of hydrogen at low temperature in the intake manifold; this could easily lower the mixture temperature before the compression process

\section{Conclusion}

The presented analytical and experimental investigation for the effects of adding hydrogen on diesel engines power output and the reduction of emissions shows obvious positive signs to follow-up the obtained results. Engine power to weight ratio can be improved at optimized hydrogen-diesel operating conditions. Carbon oxides emissions can be reduced along with the increasing of hydrogen percentage. Increasing the intake manifold pressure can improve the engine filling, however, knock limit remains an important concern. This is achievable without compromising the engine maximum efficiency, given that most engines are operated at small and part-load during normal driving conditions, which allow for introducing more hydrogen instead of the large quantity of excess air during such operation conditions that also further are improved by charge boosting. In view of the above observations, experimental investigations are further needed to be carried out to revile all technical issues and demonstrate practical solutions viability.

\section{Acknowledgements}

Acknowledgement is given to the technicians and automotive engineering students from Mechanical Engineering Department in Palestine Polytechnic University, for technical support and help in conducting the experimentation, respectively.

\section{References}

[1] Varde, K.S. and Frame, G.A. (1983) Hydrogen Aspiration in a Direct Injection Type Diesel Engine-Its Effects on Smoke and Other Engine Performance Parameters. International Journal of Hydrogen Energy, 8, 549-555. http://dx.doi.org/10.1016/0360-3199(83)90007-1

[2] Zhang, H., Lilik, G.K., Boehman, A.L. and Haworth, D.C. (2009) Effects of Hydrogen Addition on NOx Emissions in Hydrogen-Assisted Diesel Combustion. International Multidimensional Engine Modeling Users Group Meeting Detroit, MI, 19 April 2009.

[3] Adnana, R., Masjukib, H.H. and Mahlia, T.M.I. (2010) Experimental Investigation on In-Cylinder Pressure and Emissions of Diesel Engine with Port Injection Hydrogen System. International Journal of Mechanical and Materials Engineering (IJMME), 5, 136-141.

[4] Goldwitz, J.A. (2004) Combustion Optimization in Hydrogen-Enhanced Lean Burn SI Engine. Thesis, Massachusetts Institute of Technology, USA.

[5] Szwaja, S. and Rogalinski, K.G. (2009) Hydrogen Combustion in a Compression Ignition Diesel Engine. International Journal of Hydrogen Energy, 34, 441-4421.

[6] Saravanana, N., Nagarajana, G., Dhanasekaranb, C. and Kalaiselvanb, K.M. (2007) Experimental Investigation of Hydrogen Port Fuel Injection in DI Diesel Engine. International Journal of Hydrogen Energy, 32, 4071-4080. 
http://dx.doi.org/10.1016/j.ijhydene.2007.03.036

[7] Saravanan, N., Nagarajan, G. and Kalaisselvan, K.M. (2007) Experimental Investigation of Hydrogen Fuel Injection in DI Dual Fuel Diesel Engine. SAE, 2007-01-1465.

[8] Maki, D.F. and Prabhakaran, P. (2011) An Experimental Investigation on Performance and Emissions of a Multi Cylinder Diesel Engine Fueled with Hydrogen-Diesel Blends. World Renewable Energy Congress, Vol. 13, 8-13 May 2011. http://dx.doi.org/10.3384/ecp110573557

[9] Shahad, H.A.K. and Abdul-Hadi, N. (2011) Experimental Investigation of the Effect of Hydrogen Manifold Injection on the Performance of Compression Ignition Engines. World Academy of Science, Engineering and Technology, 277-282.

[10] Robert Bosch GmbH (2000) Automotive Handbook. 5th Edition, SAE Inc.

[11] Heywood, J. (1988) Fundamentals of Internal Combustion Engines. MacGrow Hill Int., 304-307.

[12] Guzzella, L. and Onder, C.H. (2010) Introduction to Modeling and Control of Internal Combustion Engine Systems. Springer-Verlag, Berlin Heidelberg.

[13] Jalal, R. and Adnan, S. (2012) Hydrogen Aspiration in Diesel Engine. Graduation Report, Palestine Polytechnic University, Hebron. 